\title{
(Schiff-Base)Mn(III)-Catalyzed Hydroxylation of $\alpha, \beta$-Unsaturated Esters Using Molecular Oxygen in the Presence of Metal Hydrides
}

\author{
Jong Seok Baik, Sung-bin Han, and Nam Ho Lee" \\ Deparmen of Chemistry and Reseurch Institute for Basic Sciences, Cheju National University, Jeju 690-756. Korea \\ "E-mail: namho(u)chejuac. $k r$ \\ Received November 11, 2005
}

Key Words : Molecular oxygen, $\alpha, \beta$-Lnsaturated esters, Oxidation, (Schill-Base)Mn(III), IIydroxylation

Molecular oxygen would be the most desirable oxidant in organic synthesis owing to its economically and environmentally favotable properlies. Therefore, various methods have long been developed to utilize the molecular oxygen as the oxidizing reagent under mild reaction conditions. We also have reported a new oxygenation method on the olelin oxidation to corresponding alcohols, where atmospheric pressure of oxygen was involved as the oxidant along with (schilf-base) Mn(III) catalyst and sodium borohydride as the co-reagent.'

As a continuing eflor in this field, we decided to examine the electron deficient olelins such as $\alpha, \beta$-unsaturated esters as the reaction substrate. Direct hydroxylation of $\alpha, \beta$ unsaturated esters would provide the $\alpha$-hydroxy esters, which comprise impottant functional groups frequently encountered in organic synthesis. Even though various preparative method on $\alpha$-hydroxy esters has been reported, relatively few reports have been made utilizing molecular oxygen as the oxidant for the synthesis of $\alpha$-hydroxy esters. ${ }^{2}$

In order to obtain the optimized reaction conditions in this study, we have examined some experimental parameters such as (schifl-base)Mn(III) complex, reaction solvent and reaction temperature. The optimized reaction condition was described in Table 1, where Mn(III) complex 1 (10 mol\%) was employed as the catalyst under atmospheric pressure of oxygen along with two equivalents of sodium borohydride. The reaction was carried out using chloroform as a solvent at $0^{\circ} \mathrm{C}$.

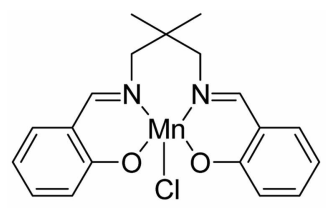

1

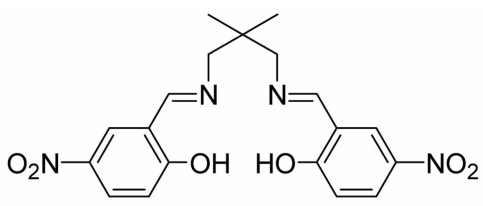

2
Some $\alpha_{4} \beta$-unsalurated esters were subjected to the above reaction conditions, and the results are summarized in Table 1. As seen in the Table, the examined unsaturated esters proved to be good substrates for the given oxygenation condition. t-Tutyl acrylate (3) was converted to the corresponding alcohol 9 in $73 \%$ isolated yicld along with small amount of reduced product, t-butyl propionate. Methacrylate compounds 4-6 were also converted to the
Table 1. The oxygenation of some $\alpha, \beta$-unsaturated esters

Olefins $+\mathrm{O}_{2}(1 \mathrm{~atm})+2 \mathrm{NaBH}_{4}+10 \mathrm{~mol} \%$ cat. $1 \frac{\mathrm{CHCl}_{3}(4 \mathrm{~mL})}{\mathrm{O}^{0} \mathrm{C} .4 \mathrm{hr}}$ Product

Eintry

"GC. yicld using dodecane as an internal standard. "Lsing $15 \mathrm{~mol} \%$ schifl-base ligand 2 along with $15 \mathrm{~mol} \% \mathrm{Mn}(\mathrm{III})$ acetote as the catalyst insteal of complex 1

corresponding tertiary alcohols 10-12 in good yiclds. Hexyl tigrate (7), where double bond is located intemally, also proved to be good substrate to give the ex-hydroxy ester 13 in $74 \%$ yield. When the $\beta$-methyl acrylate (8) was examined under the reaction condition, the expected product was obtained in only $36 \%$ yicld. In order to improve the product yicld, examination of other diflerent reaclion conditions was made. As a result, yield improvement up to $75 \%$ was observed when the calalyst 1 was replaced by direct addition of manganese(III) acetate coupled with electron deficient schifl-base 2 as the external ligand (entry 6 ) $^{3}$

During the study of this oxidation process, we observed that ester group is reduced by sodium borohydride under some solvent condition. For example, lauryl methacrylate (5) was reduced to the alcohol in $11 \%$ yield when 
Table 2. Oxygenation of $\alpha, \beta$-unsaturated esters under different metal hydrides

\begin{tabular}{|c|c|c|c|c|c|c|}
\hline \multicolumn{4}{|c|}{ Olefins + Hydrides $+10 \mathrm{~mol} \%$ complex 1} & \multicolumn{2}{|c|}{$\mathrm{O}_{2} 4 \mathrm{hr}$} & \multirow{2}{*}{$\begin{array}{l}\text { Products } \\
\begin{array}{l}\text { Yicld } \\
(\%)^{\circ}\end{array}\end{array}$} \\
\hline Entry & Olelins & Hydrides & Temp. & Solvent & Products & \\
\hline 1 & 5 & $2 \mathrm{NaRH}_{1}$ & $0^{\circ} \mathrm{C}$ & $\begin{array}{l}\mathrm{Cl} \mathrm{CCl}_{3} \\
(4 \mathrm{mI})\end{array}$ & 11 & 83 \\
\hline 2 & 5 & $2 n-B u{ }_{1}, N_{B} H_{-}$ & $0^{\circ} \mathrm{C}$ & $\begin{array}{l}\mathrm{Cl}_{\mathrm{CO}} / \mathrm{C} \mathrm{tOH} \\
(4 \mathrm{~mL} / \mathrm{l} \mathrm{mL})\end{array}$ & 11 & 79 \\
\hline 3 & 5 & & $\mathrm{rt}$ & $\begin{array}{l}\text { l- } \mathrm{PrOH} / 5 \mathrm{tOl}] \\
(2 \mathrm{~mL} / 2 \mathrm{~mL})\end{array}$ & 11 & 76 \\
\hline 4 & 7 & $2 \mathrm{NaI3II}_{4}$ & $0^{\circ} \mathrm{C}$ & $\begin{array}{l}\mathrm{CHICl}_{3} \\
(4 \mathrm{~mL})\end{array}$ & 13 & 74 \\
\hline 5 & 7 & $2 n-B u_{4} \cdot \mathrm{NBII}_{4}$ & $0^{\circ} \mathrm{C}$ & $\begin{array}{l}\text { (CHCl- } \mathrm{FtOH} \\
(4 \mathrm{ml} / 1 \mathrm{ml})\end{array}$ & 13 & 73 \\
\hline 6 & 7 & I.2 PhSil ${ }_{3}$ & $\mathrm{rt}$ & $\begin{array}{l}f-\mathrm{PrOl} / \mathrm{LtOl} \\
(2 \mathrm{~mL} / 2 \mathrm{~mL})\end{array}$ & 13 & $32\left(50^{\prime h}\right.$ \\
\hline
\end{tabular}

"Isolated yield. "Conversion yield detected by (iC.

acetonitrilc/cthanol were used as co-solvent at room temperature. This observation led us to examine other metal hydrides as a more mild hydride souree. We examined tetrabutylammonium borohydride and phenyl silane as a potential melal hydride applicable in this system (Table 2). Using esters 5 and 7 as the substrates, tetrabulylanmonium borohydride provided the comparable result compared to sodium borolydride (entries 2,5 ), which indicates that this reagent can be the substitute for sodium borohydride depending on the experimental condition. When the substrate 5 was examined under ${ }^{\prime} \mathrm{PrOH}$ and ethanol as the solvent at rt, phenyl silane also proved to be the good hydride souree (entry 3). For the above two cases, reduction at the carboxylate group was not observed (entries 2 and 3 in Table 2). In the case of the substrate 7, however, phenyl silane gave the lower reactivity compared to borohydrides (entry 6). It seems that different combination of schiff-base ligand is necessary for phenyl silane as the hydride source, on which we need further study in due course.

In conclusion, we have demonstrated that $\alpha, \beta$-unsaturated esters were oxygenated to the corresponding $\alpha$-hydroxy esters in good yields. Atmospheric pressure of oxygen was used as the oxidizing agent coupled with (schiff-base) $\mathrm{Mn}$ (III) catalyst in the presence of metal hydrides such as borohydrides or phenyl silane. This reaction provides a mild method for the direct preparation of $\alpha$-hydroxy carboxylates starting from $\alpha, \beta$-unsaturated esters. Further studies to extend the scope of this method as well as to identify the detailed reaction mechanism are underway.

\section{Experiment Section}

Typical experimental procedure. In a $50 \mathrm{~mL}$ round bottom flask were placed lauryl methacrylate $(5,254 \mathrm{mg}, 1.0$ mmol), (schiff-base)Mn(III)C. complex 1 (39 mg, 0.1 mmol), and $\mathrm{CHCl}_{3}(4 \mathrm{~mL})$ as a solvent. After oxygen balloon was adapted to the reaction flask, flushing the vessel with $\mathrm{O}_{2}$ was undertaken by evacuation/charging procedure three times. To this was added via syringe $\mathrm{NaHH}_{4}(74 \mathrm{mg}, 2$ mmol) dissolved in $4 \mathrm{~mL}$, ethanol over $20 \mathrm{~min}$ with stirring. After the mixture was stirred for $4 \mathrm{hr}$ at $\mathrm{rt}$, it was poured into sat. $\mathrm{NH}_{4} \mathrm{Cl}$ solution and extracted witl diethyl eller. The organic layer was dried with $\mathrm{Na}_{2} \mathrm{SO}_{4}$, coneentrated in vacuo and purified by flash column ehromatography to give 2hydroxy-2-methyl-propionic acid dodecyl ester $(11,226 \mathrm{mg}$, $83 \%$ yield) as the product. The structure were confirned by NMR data.

Compound 9: 'H NMR (C.T)Cl, $400 \mathrm{MH} z) \delta 4.11(1 \mathrm{H}$, dd, $J=13.7,6.8 \mathrm{H} \%), 1.46(9 \mathrm{H}, \mathrm{s}), 1.34(3 \mathrm{H}, \mathrm{d}, J=6.8 \mathrm{H} \%)$ ${ }^{13} \mathrm{C}$ NMR (CDCl $\left.13,100 \mathrm{MH} \%\right) \delta 175,26,82.32,67,11,28.14$, 20.67 .

Compound 10: 'H NMR (CDCl $3,400 \mathrm{MH} z) \delta 4.15(2 \mathrm{H}$, t. $J=6.8 \mathrm{H} \%), 1.37(6 \mathrm{H}, \mathrm{s}), 1.32(3 \mathrm{H}, \mathrm{l}, J=7.1 \mathrm{H} \%) ;{ }^{13} \mathrm{C}$ NMR (CDCI $3,100 \mathrm{MH} \%) \delta 177,3,72.1,61.68,27.21,14.19$.

Compound 11: ${ }^{1} \mathrm{H}$ NMR (C.DCl, $\left.400 \mathrm{MH} z\right) \delta 4.15(2 \mathrm{H}, \mathrm{1}$, $J=6.8 \mathrm{H} /), 1.65(2 \mathrm{H}, \mathrm{tt}, J=7.1,6.8 \mathrm{H} \%), 1.44(6 \mathrm{H}, \mathrm{s}), 1.28$ $(18 \mathrm{H}, \mathrm{m}), 0.8684(3 \mathrm{H}, \mathrm{t}, J=7.1 \mathrm{H} \%) ;{ }^{13} \mathrm{C}$ NMR $\left(\mathrm{CDCl}_{3}, 100\right.$ $\mathrm{MH} /) \delta 177.56,71.88,65.87,31.86,29.58,29.57,29.49$, $29.43,29.29,29.11,28.46,27.13,25.71,22.64,14,07$.

Compound 12: 'H NMR (CDCl, $400 \mathrm{MH} \%) \delta 7.38(5 \mathrm{H}$, m), 5.22 (2H, s), $1.47(6 \mathrm{H}, \mathrm{s}){ }^{1}{ }^{\mathrm{i}} \mathrm{C}$ NMR $\left(\mathrm{CDCl}_{3,} 100 \mathrm{MH} x\right)$ $\delta 177.56,135.57,128.77,128.57,128.13,72.23,67.46,27.29$

Compound 13: 'H NMR (CDCl $3,400 \mathrm{MH} z) \delta 4.15(2 \mathrm{H}$, $\mathrm{t}, J=6.8 \mathrm{H} \%), 1.76(1 \mathrm{H}, \mathrm{m}), 1.42(3 \mathrm{H}, \mathrm{m}), 1.37(3 \mathrm{H}, \mathrm{s}), 1.29$ $(6 \mathrm{H}, \mathrm{m}), 0.86(6 \mathrm{H}, \mathrm{m}) ;{ }^{13} \mathrm{C}$. NMR $\left(\mathrm{CDCl}_{3}, 100 \mathrm{MH} \%\right) \delta$ $177.2,74.78,65.77,32.97,31.23,28.44,25.6,25.37,22.4$, $13.85,7,86$.

Compound 14: 'H NMR (C.DCl, $400 \mathrm{MH} z) \delta 4.17(\mathrm{H}$, dd, $J=12.7,6.8 \mathrm{H} \%), 4.18(2 \mathrm{H}, \mathrm{m}), 1.82(1 \mathrm{H}, \mathrm{m}), 1.66(3 \mathrm{H}$, m) $1.32(6 \mathrm{H}, \mathrm{m}), 0.95(3 \mathrm{H}, \mathrm{L}, J=7.5 \mathrm{H} \%), 0.87(3 \mathrm{H}, \mathrm{t}, J=$ $6.8 \mathrm{H} z) ;{ }^{13} \mathrm{C}$ NMR $\left(\mathrm{CDCl}_{3}, 100 \mathrm{MH} \%\right)$ o 175.49, 71.56, $65.87,31.5 .28 .68,27.66,25.62,22.65,14.01,9.05$.

Acknowledgment. This work was supported by grant $\mathrm{No}$. R05-2004-000-10156-0 from the Korea Science \& Engineering Foundation.

\section{References and Notes}

I. (a) I.ec, N. I1; Baik, J. S.; I Jahn, S.-B. Bull Koroch Chem. Soc 1999, 20, 867. (b) L.ee, N. H.; Byun, I. C.; Baik, J. S.; Han. C.-F.; I lan, S.-B. Bull. Korean Chem. Soc, 2002, 23, 1365. (c) lece, $N$ H.; Baik, I. S.: Hahrı, S.-B. Bull. Korew Chem. Soc. 2004, 25. 1455 .

2. (a) Inoki, S.; Kato, K.; Isayama, S:; Mukaiyama, T, Chem. Lett. 1990. 1869. (b) Magnus, P.; Payne, $\Lambda$. JI.; Waring, M. J.: Scott, D A.: Lynch, V. Tetrahedron Lett. 2000, 41,9725.

3. It has been shown that employment of difterent external ligand provided reactivily change in this oxidation system. for the example, see reflc. 